\title{
Burnout: A Smouldering Problem Amongst South African Speech- Language Pathologists and Audiologists?
}

\author{
Marilyn Swidler \& Eleanor Ross \\ Department of Speech Pathology \& Audiology \\ University of the Witwatersrand
}

\begin{abstract}
The present study aimed to investigate the frequency of burnout occurring within the profession of speech-language pathology and audiology and to examine possible work situation factors unique to the profession, that may be correlated with burnout. A cross-sectional postal survey research design was used, including a standardised measure of burnout as well as a questionnaire inquiring about demographic and work situation variables. Subjects were randomly drawn from names obtained from the South African Medical and Dental Council. Results were analysed statistically using Pearsons correlations, Multivariate Analysis as well as Bonferroni T-tests. The main finding that emerged was that, as a group speech-language pathologists (SPLP's) and audiologists in South Africa are experiencing moderate levels of emotional exhaustion, low levels of depersonalisation as well as high levels of personal accomplishment. Therapists working in hospitals, mainly treating peripheral hearing disorders, working either as audiologists only or speechlanguage therapists and audiologists, with heavy caseloads and extensive paperwork, and perceiving themselves to be under large amounts of work pressure, appear to be the most susceptible to burnout.
\end{abstract}

\section{OPSOMMING}

Die huidige studie het ten doel om die frekwensie van uitbrand ("burnout") binne die beroep van spraak-taalpatologie en oudiologie te ondersoek en om moontlike werksituasiefaktore wat uniek is aan die beroep en met uitbrand gekorreleer kan word, uit te lig. 'n Veldopname navorsingstegniek is gebruik tesame met 'n gestandaardiseerde uitbrandmeting asook ' $n$ vraelys aangaande demografiese en werksituasie veranderlikes. Proefpersone is toevallig geselekteer uit name van beroepslede wat van die Suid-Afrikaanse Mediese en Tandheelkundige Raad verkry is. Resultate is statisties geanáliseer. Die belangrikste bevinding was dat spraak-taalterapeute en oudioloë in Suid-Afrika as ' $n$ groep redelike vlakke van emosionele uitputting, lae vlakke van persoonlikheidsaftakeling, asook hoë vlakke van persoonlike bekwaamheid ervaar. Terapeute wat in hospitale werksaam is en veral die wat perifere gehoorafwykings behandel, wat as oudioloë of as spraak-taalterapeute en oudioloë werksaam is, wat swaar pasiënt-ladings en uitgebreide administratiewe skryfwerk hanteer, en wat hulself ag as om onder groot werksdruk te wees, blyk die mees vatbaar vir uitbrand te wees.

The term "burnout" was originally coined by Freudenberger in 1974 and was subsequently defined by Maslach (1982) as a syndrome which results in a state of emotional exhaustion, depersonalisation, and reduced personal accomplishment among individuals who work with people. Although burnout has seldom, if ever, been documented in the research literature on South African Speech-Language Pathologists (SPLP's) and Audiologists, it seemed unlikely that these professionals would be immune from this phenomenon-- particularly given the stressful nature of their work with communicatively-impaired persons, and the unique socio-economic and politico-cultural context in which they are expected to practise their profession.

Cherniss (1980), summarises burnout as a process beginning with excessive and lengthy levels of job stress, leading to strain in the worker, i.e. feelings of tension, irritability, fatigue and emotional exhaustion. The second stage of the process occurs when workers defensively cope with the job stress by detaching themselves from the job psychologically, developing depersonalised attitudes and becoming apathetic, cynical and rigid towards their clients. The final stage occurs when caregivers develop a sense of failure and inadequacy regarding their inability to relate to clients and experience a sense of reduced personal accomplishment.

The symptoms or effects of burnout can be classified into three dimensions: physical effects (e.g. headaches, insomnia, gastro-intestinal disturbances and susceptibility to illnesses); psychological effects (e.g. emotional exhaustion, negative attitude changes and apathy); and behavioural effects(e.g. lower work productivity, absenteeism, drug and alcohol abuse and an assumed deterioration of patient care (Maslach \& Jackson, 1981; Van Der Ploeg, Van Leeuwen \& Kwee, 1990). In addition to the effects on the individual person, the burnout sufferer's family may be affected in terms of increased friction and tension in the home (Barling, 1986). 
Finally, burnout may affect employing organisations which receive poor work performance and low productivity from their employees and have to deal with high rates of absenteeism and staff turnover. It can thus be seen that burnout has individual, institutional and familial repercussions thereby affecting the whole of society.

Furthermore, from an ecological perspective, burnout is viewed as an imbalance between environmental demands and people's stress-coping resources, and causes or correlates of burnout may occur anywhere within the ecological system including the individual person, the organisation or work environment, and the broader socio-cultural milieu.

\section{The Person}

Individual factors and personality characteristics play a role in the burnout process. For example, age, gender, marital status and the number of years working experience have been correlated with burnout (Bernstein, 1992). Burnout among human service workers has been found to be significantly correlated with neurotic anxiety, unrealistic goals and low self-esteem (Ratcliff, 1988). Furthermore research has correlated burnout with personality factors such as locus of control, hardiness, and Type A personality. For example, Cherniss (1980) suggested that persons with an external locus of control, i.e. people who believe that their lives are influenced by external forces, were more likely to experience burnout; while Kobasa (1979) maintained that persons with high levels of hardiness tended to be resistant to stress because their personalities were characterised by a commitment to personal values, a sense of control over their lives, and a view of change as a challenge. Type A behaviour is the term used to describe people who are intensely ambitious, hard-driving, impatient and aggressive with a keen sense of time urgency. Although people of this type tend to be highachievers, they tend to experience more heart attacks and be more susceptible to stress than the placid, relaxed Type B person (Cooper and Davidson, 1991). In addition to personal attributes, factors within the work environment can also potentially contribute to burnout.

\section{The Work Environment}

Cherniss (1980), believes that differences in jobs and organisations are stronger etiological factors of burnout than are differences in individual characteristics or personality. He is supported by Maslach (1982), who believes that although personality plays a part in burnout, the phenomenon is best understood and modified in terms of situational sources of job related, inter-personal stress. Maslach (1982) believes that burnout is a unique form of stress, in that it is a response to the chronic emotional strain of working extensively with other human beings, particularly when they are experiencing problems.

SPLP's and audiologists do not only deal with communication and hearing problems, they deal with people who also exhibit emotional and physical problems which need to be dealt with in therapy and which can be accompanied by possible negative attitudes on the part of patient and therapist. Moreover therapeutic work is usually demanding and emotionally draining. It is difficult to assess the degree of therapeutic success in the helping professions and how much time is required to see progress in therapy. Most human service work, compared with other types of work, offers very little feedback, thus the therapist must work in the dark, not knowing the success of his or her efforts. A lack of therapeutic success has been cited as one of the most stressful aspects of therapeutic work (Maslach,1982).

Miller and Potter (1982), investigated stress among a sample of 123 members of the American Speech-Language-Hearing Association. They found that $43 \%$ of their respondents reported themselves to be moderately burned out. A survey conducted by Van der Gaag (1988), as cited by Kersner and Stone (1991), found that $99 \%$ of District Speech Therapy Managers in the United Kingdom felt that stress levels in the profession had increased in the last few years. Moreover, this problem was cited as a major factor affecting the performance of the speech therapists. According to Fimian, Lieberman and Fastenau (1991), who formulated a burnout scale specifically for Speech-language pathologists working in schools found that increasing demands for accountability, together with large caseloads, excessive paperwork, and feelings of isolation, would appear to make SPLP's and audiologists especially prone to stress and burnout. These researchers point out that SPLP's cannot be expected to function effectively if suffering from excessive fatigue, headaches and other reported symptoms of stress. It is of interest that Fimian et al., (1991, p.444), found stress scores in their sample, to be highly correlated with "bureaucratic restrictions, time and workload management and lack of professional supports". Kersner and Stone (1991), found that speech therapists as compared to Occupational and Physical therapists in the United Kingdom experienced the size of their caseload and feelings of isolation as stressful. In fact a very high proportion of their respondents, namely $82 \%$, reported being stressed at work.

The findings from these three overseas studies of stress and burnout within the profession of Speech-language Pathology highlight the need for SPLP's and audiologists' stress symptoms to be taken seriously and for the underlying etiologies to be addressed. These findings also lend support to Cherniss's contention that factors within the work environment play a crucial role in the development of burnout.

Among the work setting variables that have been implicated in previous research as possible correlates or moderators of the burnout syndrome are social support, workload and clientele.

Cobb (1976) defines social support as information leading the individual to believe that: 1) he or she is cared for and loved (emotional support), 2) he or she is esteemed or valued (esteem support), and 3 ) he or she belongs to a network of communication and mutual obligation (network support). According to the buffering hypothesis, as cited by Ross, Altmaier and Russell (1989), persons involved in supportive relationships are able to rely on others to help them when dealing with stress, a resource likely to lessen the adverse effect of stress on physical and mental health. Several researchers cited by MacFarlane (1990), emphasised that social support from co-workers and supervisors is one of the most effective ways to alleviate negative effects of organisational stress. 
A further important work variable is that of work load. According to Maslach (1982), a large case load means that less time can be spent on each case, fewer services may be provided and there may be little or no follow-up. The helper may develop a quick and emotionally withdrawn method of dealing with her clients to try and avoid the emotional strain of dealing with so many people. This inadequate care provided may in turn induce feelings of inefficiency, failure and a lack of personal accomplishment and thus a large case load may represent a major source of burnout. Fimian et al. (1991, p.433), found that "Time and Workload Management" questions, consisting of items dealing with SPLP's perceptions of time at work, accounted for $32 \%$ of the stress variance. High scorers on this factor reported having "too much work to do, no time to get things done, little time to prepare, little time for personal priorities, and too much paperwork."

One also needs to look at the effect of the type of clientele on the frequency of burnout. Cherniss (1980), cites the example of helpers who have low functioning clientele. He argues that such persons are likely to believe that there is little they can do to improve their functioning leading to feelings of a poor sense of impact and efficacy. Furthermore such professional caregivers are unlikely to be able to use their clinical skills to the fullest extent and may experience their roles as less consistent with their professional identities. Tuomi (1993, p. 11), explains how quality care for the severely retarded person may just involve "doing something and maybe teaching the patient to cope with simple tasks..." These factors can have an effect on the experience of job stress and the coping reaction.

These stressors within the work environment are likely to be further exacerbated by stressors emanating from broader societal factors.

\section{The Broader Sociocultúral Milieu}

According to Handy (1988, p.354), “... the root causes of both stress and burnout are often far removed from the individual person or job and may be more appropriately conceptualised in societal and organisational terms". An ecological perspective, where stress can be viewed as a result of an imbalance between environmental demands and resources, is possibly applicable to South African SPLP's and audiologists.

Becker and Isaacs (1993, p.15), believe that "South Africa is a country in transition. There are changes in the structure of society, in terms of social change and the elimination of apartheid, and in terms of massive moves from rural to urban settlement. Concomitant with the promising aspects of societal change, there are, however, other aspects which place strain on the available health care services".

A major source of strain is poverty which has a serious impact on individuals, families, and society in general. According to Phiyega (1992), in South Africa, poverty presents itself in political unrest due to stress and conflict, violence in families and communities, unemployment, lack of provisions and lack of facilities.

Hence, there are economic, political and social stressors operating in this country at the present time. An aspect of the inadequate provision of resources cited by Beecham (1990), concerns the small number of speech and hearing therapy graduates trained in South Africa which results, from Aron's (1991) estimation of 1984 figures, in therapeutic services reaching only 138,000 persons from a possible client population of 3.5 million. In 1986, a survey conducted by the Department of National Health and Population Development found the following: In respect of so called "coloured" people, there was a shortage of 520 therapists. For Asians the shortage was 139 while the shortage for the Black population group was 3396. Aron (1991), provided the following statistics: 223,200 persons with communication disorders receive attention in a period of a year, however, there are approximately three million who have communication disorders. Clearly the ratio of therapists to patients requiring therapy is not improving with time.

These figures lend support to Becker and Isaacs's (1993, p.24), contention that "in South Africa the need to cater to increasing numbers of clients needing assessment and treatment is juxtaposed with the scarcity of trained professionals in the helping professions". From the above statistics it would seem likely that practising SPLP's and audiologists are being required to work with excessively large caseloads.

Secondly, therapists have to adapt their First World training to meet the need of particular social, educational and communicative problems within South Africa's culturally diverse population. Speech therapy and audiology can no longer safely slot into a tertiary level of intervention. SPLP's and audiologists now have to shift to intervention at a primary or secondary level, in communities where these needs are not being met. This may be placing an extra burden on the therapists who no longer confine themselves to giving therapy, but also have to tackle education of communities on relevant issues.

Steenekamp (1993, p.5), states that in the light of the economic situation "there is an increasing demand for the therapist's clinical skills, with a decreasing amount of time available for other demands, eg., research, tutoring, training of students, observation and so forth. Increasing demands from other institutions are only adding to an increasing amount of stress." Aron (1991), commented on the frustration endured, defending and interpreting the profession of speech pathology and audiology to official sources, university administrators and medical personnel. She states that this in fact may be a contributing factor in the burnout syndrome.

Clearly, South African SPLP's and audiologists appear to be subject to stresses at all levels of the social system, and to factors unique to the context of this country. It therefore appeared to be both relevant and timely to investigate the occurrence of burnout within members of this profession and to endeavour to relate frequency of burnout with factors occurring at the individual or personal level, within the work environment as well as the broader sociocultural milieu.

Although Miller and Potter (1982), conducted a national survey of burnout among SPLP's, criticism can be levelled against them because of their failure to use a standardised measure of burnout, such as the Maslach Burnout Inventory (MBI). Instead they merely asked respondents "how burned out they felt".

In order to obtain more valid and reliable data on stress symptom levels in the profession, Fimian et al., 
(1991), developed the Speech-Language Pathologist Stress Inventory (SLPSI). More specifically, they constructed . "... an instrument designed to measure job related sources and manifestations of stress experienced by speech-language pathologists in the schools..”. These researchers attempted to adapt the MBI to speech pathologists. A possible weakness with the SLPSI is that the authors averaged scores from individual subscales to yield a Total Burnout Scale. Koeske and Koeske (1989, p.142), advise against the use of this procedure for the following reason: "Given the differential associations of the three subscales with one another and with other measures, researchers probably should avoid computing a composite "burnout" score and instead preserve the three subscale scores and relate them separately to other measures whenever appropriate". Furthermore, this inventory was standardised on school speech-language pathologists only and may not necessarily tap possible stressors affecting speech-language pathologists in other job settings.

The present study endeavoured to improve on the methodology utilised in these three overseas studies, and to extend their scope by incorporating standardised measures of burnout, co-worker support and supervisory support and by eliciting information on the broader sociocultural factors unique to South African SPLP's and audiologists. Furthermore, it was hoped that the study would add to the theoretical knowledge of burnout and possibly provide practical suggestions for reducing the potentially deleterious effects on SPLP's and audiologists, their employing organisations and their clients.

\section{METHODOLOGY}

\section{AIMS}

The aims of the study were:

(1) To investigate the frequency of burnout occurring among speech-language pathologists (SPLP'S) and audiologists.

(2) To determine the relationship between frequency of burnout and certain personal characteristics and work situation variables specific to SPLP'S and audiologists.

\section{INDEPENDENT VARIABLES} Personal Factors: Gender

Work Experience

\section{DEPENDENT VARIABLES \\ Burnout:}

Emotional Exhaustion

Depersonalization

Reduced Personal

Accomplishment

Organisational Factors:

Caseload

Place of: Work

Type of Impairment Treated

Severity of Impairment Treated

Adult/Child

Working as SPLP/Audiologist

Paperwork and Administration

Language of Client

Broader sociocultural factors perceived to contribute to the experience of stress, were analysed descriptively and were not included in the statistical analysis as no standardised scale is available to measure the phenomenon.

\section{SUBJECTS}

\section{Subject Selection Criteria}

A random probability sample of 500 names was drawn from the register of SPLPs and audiologists in the Republic of South Africa registered with the S.A. Medical and Dental Council as at June 1992. Krejcie and Morgan as cited by Christenson (1980, p.299), suggest a sample size of 270 people to be an adequate representation of the total population of 852 people.

\section{Description of Subjects}

The sample comprised 500 therapists, $98 \%$ of whom were female and $2 \%$ were male. Extent of work experience ranged from 1 year to 40 years with a mode of 11 years. With regard to place of work, $35 \%$ of respondents were employed in schools; $32 \%$ in private practice; $10 \%$ in hospitals; $7 \%$ in universities; and $16 \%$ in other settings. Type of impairment treated was broken down as follows: language-learning disabilities $27 \%$; language $20 \%$; peripheral hearing loss $10.5 \%$; central hearing loss $2 \%$; articulation $8 \%$; fluency $5.5 \%$; traumatic brain injury $2 \%$; mental retardation $3 \%$; aphasia $1.5 \%$; and other $2 \%$. The vast majority of respondents, namely $73.5 \%$ worked with children only, while $4.5 \%$ worked solely with adults, and $22 \%$ provided services for both children and adults. In terms of the focus of intervention, only $7 \%$ of the sample were employed solely as audiologists; $44 \%$ worked only as speech pathologists; while $49 \%$ fulfilled the dual role of SPLP and audiologist.

\section{RESEARCH PROCEDURE}

\section{Research Design}

In order to investigate the aims of the study, a crosssectional, survey research design was employed which involved the use of a postal questionnaire.

\section{Description of the Questionnaire}

A 9-page questionnaire (set out in Appendix I) was constructed which could be completed in approximately 10-15 minutes. The research instrument was made available in both English and Afrikaans translations as all respondents supposedly received their tertiary level education in either of these languages. A covering letter explained the purpose of the questionnaire, provided assurance of confidentiality, and clarified how and when to return the questionnaire. The questionnaire comprised the following sections: demographic information; open-ended questions on the respondent's perceptions of the influence of certain factors on stress and stress-coping strategies used by the respondents; subscales from Moos and Insel's Work Environment Scale; and the Maslach Burnout Inventory. These sections were included in order to provide information on the relationship between the frequency of burnout being experienced, and biographical as well as work environment variables of the SPLP's and audiologists. Each section is described separately as follows: 


\section{Demographic Information}

The aim of this section of the questionnaire was to solicit biographical information, namely respondent gender as well as data on factors such as job setting, caseload size, type of impairment, respondents subjective perceptions of severity of client's communication impairment and the amount of time spent on administration of paperwork.

\section{Open Ended Questions}

This section of the questionnaire included items aimed to elicit respondents' perceptions of the possible influence of socio-economic and politico-cultural factors on the experience of work stress. Also included were questions soliciting information on strategies used by respondents to cope with stress. Finally, the respondents were asked whether they felt stress-management techniques should be taught to students as well as graduates.

\section{The Work Environment Scale(WES)}

The WES is a 90 -item, paper and pencil measure developed by Moos and Insel (1974), to assess the social climate of many types of work units, and focuses on relationships among employees, between employees and supervisors, and on the unit's basic organisational structure and functioning. The WES is composed of ten subscales that tap three underlying dimensions: Relationship, Personal Growth, and System Maintenance and Change.

From the Relationship dimension two sub-scales were utilised in this research, namely: Peer Cohesion, and Supervisor Support. These sub-scales assess the extent to which employees are friendly to and supportive of one another, and the extent to which management is supportive of employees and encourages employees to be supportive of one another (Moos, 1986, p.1).

From the Personal Growth or Goal Orientation dimension, one sub-scale was utilised, namely: Work Pressure. This sub-scale assesses the degree to which the press of work and time urgency dominates the work milieu (Moos, 1986).

Internal consistency calculated for each of the ten WES sub-scales using a sample of 1,045 employees, has been found to be within an acceptable range, i.e. 0.690.86 (Moos, 1986, p.4).

Importantly, Sub-scale inter-correlations indicate that the sub-scales measure distinct though somewhat related aspects of work environments. Test-retest reliability has also been found to be acceptable. Scales have also been reported to have satisfactory content and face validity as well as construct and criterion validity (Moos, 1987).

\section{The Maslach Burnout Inventory (MBI)}

The MBI, is a 22 -item self-report scale developed by Maslach and Jackson (1981). Responses involve the frequency of feelings towards each question, ranging from never $(0)$ to "every day" (6). The instrument is composed of three sub-scales measuring the three areas that Maslach and Jackson believe best define the experience of burnout, namely: emotional exhaustion, depersonalisation, and lack of personal accomplishment. The instrument is labelled "Human Services Survey" rather than "Burnout" in order to avoid biasing respondents.

The developers recommend that the inventory be presented as a survey of job-related attitudes without being connected to burnout and that anonymous responses be requested.

In view of the fact that burnout is a multi-dimensional construct, the test does not yield an overall diagnosis of "burned-out" versus "non-burned out" but instead provides three separate, non-additive scores of emotional exhaustion, depersonalisation, and reduced personal accomplishment.

Maslach and Jackson (1986) report that studies using the MBI have obtained high scores for internal consistency reliability, test-retest reliability, and convergent validity, and that the scale is free of social desirability bias.

Offerman (1985) states that the main limitations of the MBI is that it does not indicate the meaning of the score levels. The researcher needs to question what a "moderate" level of burnout means in terms of behaviour (Offerman, 1985, p.421). Nevertheless, the MBI has been in use for nearly twenty years and has been part of the methodology of hundreds of studies.

\section{Research Protocol}

\section{Pilot Study}

The questionnaire was pre-tested on a small group of English and Afrikaans speaking therapists not included in the final sample.

\section{Distribution}

i) The target population comprised 500 registered SPLP's and audiologists.

ii) In an attempt to increase the rate of returned completed questionnaires the researcher included stamped, addressed return envelopes and sent reminder cards requesting respondents to return questionnaires if they had not done so already.

\section{ANALYSIS OF DATA}

Initially the data was summarised using a univariate analysis procedure, which provided means where appropriate, standard deviations, modes, and ranges. Following this, results were analysed to establish relationships between the independent and dependent variables using inferential statistics such as Pearson Productmoment Correlations. This analysis was followed by a multivariate analysis of variance, using a General Linear Models Procedure. Finally Bonferroni T-tests were used to further analyse the data, and establish differences between sub-groups. The open-ended questions were analysed descriptively by summarising and describing common themes expressed in the responses.

\section{RESULTS AND DISCUSSION}

Although 230 questionnaires were returned only 202 were used as the remainder arrived too late to be incorporated into the statistical analysis. The response rate was therefore $40.4 \%$ which Moser and Kalton (1971), 
regard as acceptable for mail surveys. Missing data on certain measures being correlated reduced the sample size below 202. Hence sample sizes ranged from 197202 , depending on the measure being correlated. The question on the language spoken by the respondents' patients was not included in the statistical analysis, due to the ambiguity of: the responses obtained.

The first step in the data analysis involved obtaining the mean, mode, range and standard deviations of the variables. From the results it appeared that as a group SPLP's and audiologists were suffering from a moderate level of emotional exhaustion (i.e obtained a score between 17-26 on the MBI) although the range extended from a mild to high level of emotional exhaustion. The mean for depersonalisation was 3.8 indicating that as a group the respondents had a low tendency to depersonalise their patients (i.e. obtained a score between $0-6$ ). These findings indicate that respondents have not, as a whole, developed a cynical opinion of their patients, expecting the worst from them and even disliking them. Scores did, however, range from 0-22 with any score above 13 being considered as a high level of depersonalisation. The group indicated a low level of feelings of Reduced Personal Accomplishment (i.e.obtained a score between $0-31$ ) with a mean of 10.23 and scores ranging from $0-28$. These results suggest that SPLPS were feeling competent and adequate in their jobs and their ability to relate to and treat their patients. These findings also underscore the fact that despite feeling emotionally exhausted, therapists can still derive a sense of accomplishment from the work and do not necessarily experience negative attitudes towards clients. These results are also consistent with Oktay's (1992) findings that despite relatively high levels of emotional exhaustion experienced by hospital social workers who work with AIDS patients, they felt a substantially high level of personal accomplishment because of the meaningfulness of their work.

\section{Table 1. Burnout Scores}

\begin{tabular}{|l|c|c|c|c|c|}
\hline & Mean & \multicolumn{2}{|c|}{ RANGE } & Std. Dev & Mode \\
\hline & & Low & High & & \\
\hline $\begin{array}{l}\text { Emotional } \\
\text { Exhaustion }\end{array}$ & 22.2 & 0 & 52 & 23 & 10.8 \\
\hline Deperson. & 3.8 & 0 & 22 & 0 & 4.3 \\
\hline $\begin{array}{l}\text { Personal } \\
\text { Accomplish }\end{array}$ & 10.2 & 0 & 28 & 9 & 5.7 \\
\hline
\end{tabular}

The relationships between the independent and dependent variables are discussed as follows:

\section{Gender}

A negative relationship significant at the 0.05 level $(F=6.41, p<.05)$ was found between depersonalisation and gender and no significant relationship was found between gender and the other two dependent variables of emotional exhaustion and Reduced Personal Accomplishment. The research on gender and burnout is controversial with some researchers finding huge differences in the experiences of burnout between males and females and some finding very little difference. Men are reportedly more susceptible to develop callous feelings about the people they work with and hence more likely to experience depersonalisation (Maslach 1982;). The reasons offered by Maslach (1982) are that men tend less towards close contact with people. However, there is no empirical data to support this reasoning. In addition, the present sample included only four males therefore making the generalisability of gender results more difficult.

\section{Length of Working Experience}

A very significant negative relationship at the 0.01 level was found between the number of years the clinician has been working and depersonalisation, although this was not supported by the multivariate analysis ( $F=0.92, P>.05)$ or the Bonferroni T-test. Research has shown that burnout is lower among older and more experienced workers (Maslach 1982; Van der Ploeg et al.,1990; Ross \& Altmaier, 1989). It seems that it is not just a case of work experience but also the maturity and stability that accompanies increasing age. Edelwich and Brodsky (1980) suggested that newly qualified professionals are prone to experience burnout when their initial energy and ideals are eroded by the real difficulties and limitations of their profession. This could be especially true for South African trained speech therapists who are taught western techniques during their training which may no longer be appropriate in a multi-cultural society such as South Africa and when the ideal clinic situation during their university training is no longer applicable in the real job context.

Of related interest is that a highly significant relationship at the 0.01 level of confidence was found between the number of years worked and the amount of paperwork completed. Pines and Maslach (1978) as cited by Savicki and Cooley (1987) offer an explanation for the above, suggesting that as workers remain in the field longer, they tend to become less involved in direct therapy work and more involved in administration and administrative duties which may be impacting on burnout in a unique way.

\section{Place of Work}

A significant negative relationship was found at the 0.05 level $(\mathrm{F}=5.43, \mathrm{p}<.005)$ between place of work and emotional exhaustion, and a very significant relationship at the 0.01 level $(F=2.85, p<.05)$ existed between place of work and depersonalisation. T-tests revealed that therapists working in a hospital setting tended to experience more emotional exhaustion than therapists working in private practice, and therapists working in institutions experienced more emotional exhaustion than those working in private practise. These findings suggest that the clinical setting and the work environment play a role in the type and severity of stress experienced by professionals.

\section{Caseload}

Also of interest is the significant correlations at the 0.005 level between place of work and caseload and at the 0.05 level between place of work and the severity of the client treated.,These relationships possibly offer an 
explanation for the relationship between place of work and emotional exhaustion. Furthermore a significant relationship existed between place of work and depersonalisation $(\mathrm{F}=2.85, \mathrm{p}<.05)$. Hospital therapists tended to experience more depersonalisation than either school therapists or private practitioners. A very significant relationship at the 0.01 level ( $F=5.43$, $\mathrm{P}<.001$ ) was found between case load and emotional exhaustion. According to Maslach (1982, p.38), a large case load may lead to a situation of "too many people and too little time to adequately serve their needs-- a situation ripe for burnout." Furthermore larger caseloads mean that more energy is depleted in order to perform satisfactorily.

\section{Type of Impairment}

A significant relationship at the 0.05 level ( $F=2.50$, $\mathrm{P}<.05$ ) exists between the type of defect treated and depersonalisation. T-tests revealed that treating peripheral hearing disorders tended to be associated with greater depersonalisation of patients than treating both a language and a language/ learning disability. This could possibly be attributed to the fact that treating a peripheral hearing disability usually involves three or four sessions or perhaps even one diagnostic session, therefore the therapist is not afforded the opportunity to establish a relationship with her patients.

\section{Paperwork}

A very significant relationship was found at the 0.001 level ( $\mathrm{F}=2.67, \mathrm{p}<.05$ ) between the amount of paperwork completed in a week and emotional exhaustion. According to Maslach (1982), administrative tasks and paperwork can interfere with the therapists' direct work with the patient as it could take up therapy time. In fact many of the therapists reported in the open-ended questions, that paperwork often needed to be done after hours as there was usually not enough time during the workday to complete all the necessary administration. Hence long work hours may be leading to feelings of emotional exhaustion.

\section{Co-Worker Support}

A very significant relationship exists at the 0.001 level between emotional exhaustion and co-worker support. This relationship was, however, not in the expected direction. Statistical analysis of the data, revealed the presence of a few outlying values which could have grossly distorted the data, resulting in a spurious rather than a meaningful or substantive correlation.

\section{Work Pressure}

Work Pressure and emotional exhaustion were highly correlated with each other and a very significant relationship at the 0.001 level $(F=5.76, P<.001)$ existed between them. Cherniss $(1980$, p.44) maintains that "stress occurs when there is a perceived imbalance between resources and demands. Demands can be external (for instance formal job requirements) or internal (for example, personal goals, needs, and moral values)."
Since it appears that external demands such as caseload impairment treated, and lack of social support did not seem to be correlated significantly or were minimally correlated with the burnout phenomenon, it would seem that these demands are possibly internal as reported by some of the private practitioners in their open-ended questions. It is possible that practitioners were not perceiving their work demands realistically and were constantly plagued by a sense of urgency and lack of time to complete their work:

\section{Descriptive Analysis of Open-ended Responses}

\section{Question 1 - Work Stressors}

Common themes emerged in the responses of private practitioners and those working at schools and hospitals. Rules, regulations and bureaucracy, writing of detailed reports as well as inspections were considered as stressful factors at work. Those working in schools needed to use groupwork as a therapeutic technique due to time constraints and a situation of too many pupils and too few therapists and they tended to find groupwork stressful and emotionally draining. They claimed that this method was associated with poor progress of pupils due to insufficient treatment time. Poor cooperation between teachers, parents and therapists was a problem cited by many respondents. Private therapists complained of poor cooperation of parents with home programmes. They were pressurised to obtain results in a certain period of time and often parents and teachers had unrealistic expectations of therapy results. A few therapists found it stressful that patients who travel from far expect results within periods as short as in three sessions.

Furthermore, private therapists were expected to make an immediate diagnosis, leaving them no time to test thoroughly and arrive at a carefully considered diagnosis. Working in isolation was found to be extremely difficult as one cannot confirm results and diagnosis with another therapist. Financial handling of a private practice and collection of fees was reported to be highly stressful. Lack of training in certain areas of treatment was also found to be stressful for some therapists. Inadequate test materials and inappropriate standardised tests due to cultural and language biases increased the stresses of therapy. Many therapists felt that the profession has not seemed to have established itself. Some respondents highlighted the fact that one continually needed to promote the profession as there was insufficient knowledge about speech-language pathology and audiology and the contribution it can make. Time restraints and time pressure were found to be stressful by the majority of therapists irrespective of their job context. Time management was not confined to therapy but included school visits, speaking to parents, writing reports and programmes. There appeared to be little time for research and reading to keep pace with the unending amount of new information. Therapists often needed to work after hours to keep up to date with administration and paperwork. Therapists reported sometimes feeling ill-equipped to deal with emotional support and counselling during the session and the emotional difficulties involved in working with severely impaired patients who show little improvement. 


\section{Question 2 -Societal Stressors}

Handy (1988) cautions that societal and organisational causes of stress cannot be ignored simply because there are no easy solutions to solving these problems. Figure 1 indicates that $30 \%$ of the respondents felt that broader societal factors did not contribute to their experience of stress. However, among the $70 \%$ of respondents who perceived themselves to be affected by socioeconomic and politico-cultural factors, common themes were expressed.

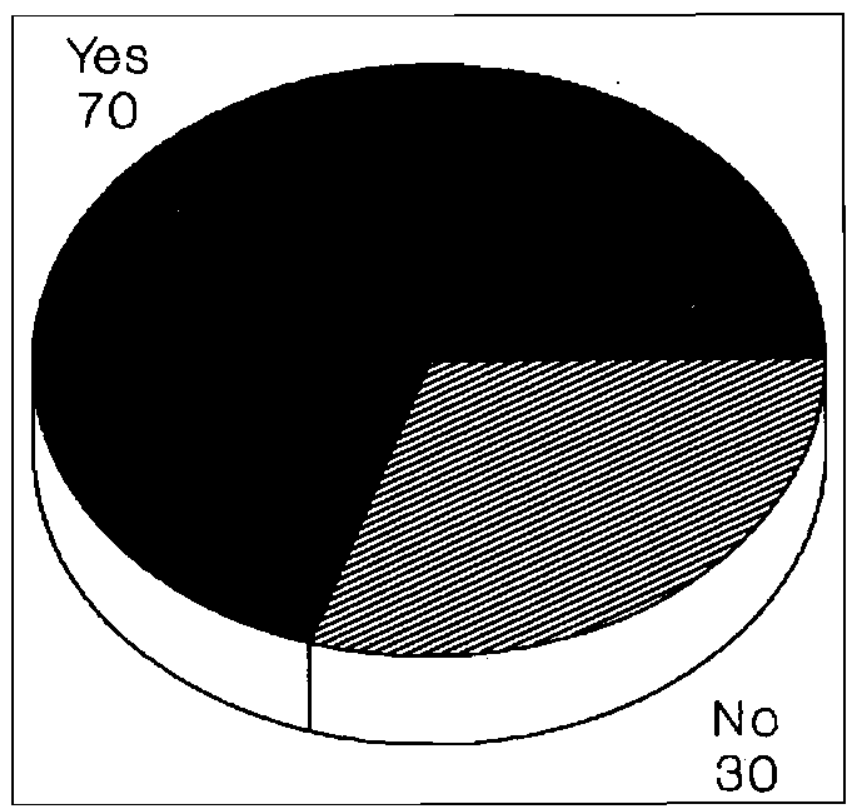

Figure 1. Affected by Sociocultural Factors.

Therapists found it stressful that children from poor economic backgrounds seem to show little progress in therapy. One of the most important demands confronting human service staff is the expectation of competence and many caregivers are motivated to achieve a sense of efficacy or psychological success in their work (Cherniss, 1980). Lack of progress in therapy might therefore be stressful for therapists. The respondents attributed this occurrence to poor parental education levels, the fact that patients often do not attend therapy, follow home programmes or advice given and do not understand the implications of the disorder. In addition to this, caregivers often have to work and there is little stimulation in the home. Another related issue was that many patients cannot afford to come regularly to ther apy. Furthermore, new medical aid cutbacks have frequently required reducing the number of therapy sessions and thus therapists feel that because of rising costs they are more accountable to achieve rapid results. Many therapists were also distressed at the prospect of not being able to treat patients who could not afford clinic fees.

Several respondents reported that for those therapists not in private practise, the number of posts available has been reduced resulting in large workloads and little job satisfaction.

Salaries have been cut or are not being increased making it difficult to meet the rising cost of living. Political unrest results in therapists fearing for their safety and the security of their families. A few therapists found that travelling to work was stressful as they feared rioting or being attacked. The above are examples of physical work stressors which can potentially influence workers' perception of job comfort.

There appeared to be uncertainty as to the future of the profession in a Third World country where primary needs are not being met. There is often a lack of reliable transport to and from the townships and violence and stayaways seriously disrupt provision of services. The poor economy and uncertain politics-- including political differences among co-workers, impacts on enthusiasm and ease of working conditions.

From a sociocultural point of view therapists remarked on the difficulty of working with patients from different cultures and different languages. Person-role conflict can contribute to burnout (Cherniss, 1980). Many therapists indicated that they felt unprepared to work with other communities because they lack the necessary knowledge and skills. The implications of these findings are that if the SPLP's and audiologists are not adequately trained for new role demands, the consequences are likely to be high levels of person-role conflict, job stress, dissatisfaction and burnout (Cherniss, 1980).

Some therapists commented on the language barrier between teachers and therapists and the difficulty in advising teachers on how to handle second language learners. On the other hand those therapists serving only white South Africans were concerned that they were not addressing the needs of the larger community. Furthermore, many of the children treated live with their grandparents and subsequently it was difficult to obtain medical and genetic histories. Finally, parents may not bring their children for an assessment until they are older and the problem has become compounded and multifaceted and in some cases resulting in poor prognoses.

\section{Question 3 -Stress-coping strategies}

"Coping refers to changing cognitive and behavioral efforts used to manage internal or external demands perceived as exceeding the resources of the individual" ( Folkman, Lazarus, Gruen \& De Longis, 1986, p.23). Strategies used to cope with stress varied and appear to be highly individualistic. Common techniques utilised involved regular exercise, time away from work, religious beliefs as well as careful planning and organisation of work schedules and demands. Some negative strategies such as smoking, overeating and drinking coffee were also reported.

\section{Question 4 - Stress-management course during training}

The majority of respondents, namely, $62 \%$ of the respondents felt that a stress management course should be incorporated into the training curricula of speechlanguage and hearing pathologists. Others felt that the course was too full and that to include another subject would only serve to increase the stress experienced by students. Furthermore, it was felt that if time was available it should rather be útilised for areas that were not taught in detail. Others felt that such a course would be useless without specific job experience, and that different work contexts cause different forms of stress. 
Wilder and Plutchik cited in Paine (1982, p.115) agree, believing that “ just giving knowledge to professional trainees about stress and the phenomenon of burnout during training will probably have few long term effects".

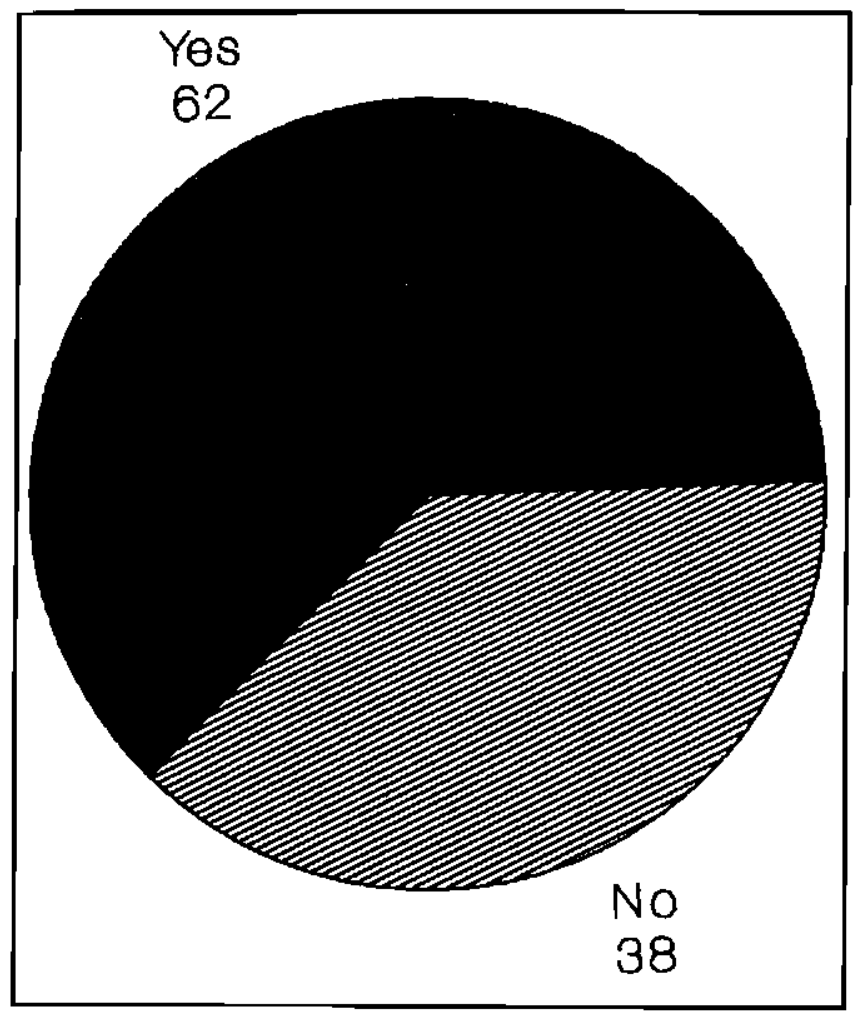

Figure 2. Stress Management Course for Students.

\section{Question 5 -Stress-management course for quali-} fied therapists

A high proportion of respondents, namely $80 \%$, felt that a stress-management/course should be made available for qualified speech-language and hearing pathologists. It was, however, specified by many respondents that this course should not be run by fellow speech-language therapists and audiologists as the subject matter was regarded as too personal. Among those who felt the course was unnecessary, reasons given were that

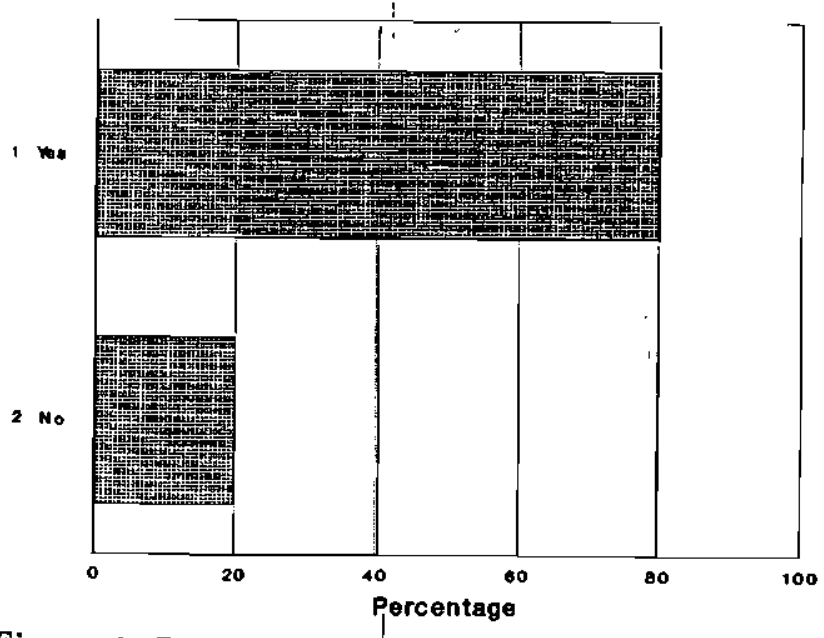

Figure 3. Stress Management for Qualified Therapists stress management is a personal choice and is too varied to apply to everyone.

\section{CONCLUSIONS}

The data suggest that although moderate levels of burnout characterised the sample on average, certain job characteristics tended to make SPLP's more susceptible to this experience. Furthermore, despite the fact that many respondents were subject to difficult work conditions which tended to give rise to feelings of emotional exhaustion, the majority of therapists reported deriving a sense of accomplishment from their work and relatively low levels of depersonalisation.

It is important to note that this study provided correlational data and thus no conclusions about causal relations among socio-demographic factors, work setting variables and burnout can be drawn. Nevertheless, the findings from the study do have implications for clinical practice and job design; research; and the training and continuing education of speech-language pathologists and audiologists.

\section{Clinical Practice and Job Design}

In view of the fact that certain job settings such as hospitals, appear to contain more potential for job stress than other contexts, it is recommended that employers of SPLPS and audiologists pay attention to the structure and design of the job. For example, support meetings, informal case discussions, supervision and buddy or mentorship systems are alternate strategies that could possibly be built into work structures. These support mechanisms would appear to have particular relevance to newly qualified therapists with limited work experience who were shown to be particularly prone to experience high rates of depersonalisation. It is also suggested that care be taken to control the number of difficult cases allocated to therapists and the supervision of those cases.

Moreover, in view of the significantly high correlation between depersonalisation and treatment of peripheral hearing disorders, it is recommended that-- where practically feasible-- supervisors endeavour to allocate a wide range of patients with different types and degrees of communication impairment to the therapists in their employment. In addition, the complaint expressed by a large number of respondents regarding excessive paperwork, suggests the need for employers and clinicians to brainstorm ways of possibly streamlining routine administrative tasks, particularly in large bureaucratic organisations.

\section{Research}

It is recommended that future studies incorporate personality variables into the research design and analysis as these factors may predispose some SPLPs and audiologists to be susceptible to burnout. It is possible that certain personality characteristics are looked for in the selection procedures for training in the profession or- to quote one respondent- "Perhaps the feeling of work pressure instilled in us during our training, is an image that we carry with us into the 'real' world, thus affecting our perceptions of work demands." 
Another important aspect which was omitted from the statistical analysis in the present study and which needs to be researched, was the effect of languages spoken by the clients of SPLPS and audiologists on burnout. Furthermore a subjective measure of client communication impairment was utilised in this study. It is suggested that future research endeavours to incorporate more objective measures of this variable.

A further fruitful area for future research is the different coping styles adopted by speech-language pathologists and audiologists as they can influence how individuals respond to stress.

The present study focused on general work stresses experienced by a national sample of therapists working in various job settings. Future research needs to focus on specific stresses associated with specific job contexts such as AIDS patients, neurological disorders and so forth.

A further limitation of the study centred on the use of the Work Environment Scale which measures perceptions of respondents regarding their work milieu. Perceptions may have been unintentionally distorted or subjects might have provided socially desirable answers. For this reason future research could probably incorporate more objective indices of the job by focussing on the actual number of cases seen each week, and the actual time devoted to paperwork.

\section{Training and Continuing Education}

The fact that $62 \%$ of the respondents were in favour of a stress management course being incorporated into the undergraduate training curriculum and $80 \%$ felt that a course should be made available to qualified SPLPs and audiologists, underlines the need to address this gap in professional education.

In conclusion, it is hoped that this study offers important guidelines for future research and the development of intervention programmes and for future research and education. If speech pathologists and audiologists are to survive the demands of the 1990's, and are to continue to be influential and effective professionals, they will need to identify and manage stress. related problems before the impact of these problems becomes excessive and their solution difficult.

\section{ACKNOWLEDGEMENTS}

Financial assistance received from the S.A. Speech-Language and Hearing Association towards the costs of the study, is acknowledged with appreciation.

\section{REFERENCES}

Aron, M.L. Perspectives. (1991) The South African Journal of Communication Disorders. 38, 3-11.

Barling, J. (1986). Some Consequences of Paid Employment. In J. Barling, C. Fullager \& S.D. Bluen (Eds.). Behavior in Organisations: South African Perspectives. 2nd ed. Johannesburg: University of the Witwatersrand.

Becker, L. \& Isaacs, G. (1993), Brief dynamic psycho-therapy: An exploration of attitudes and practice among a group of clinicians in Cape Town, South Africa.Some implications for training. Social Work, 29(1), 14-31.

Beecham, R. (1990). Training and Context: Perceptions of South African Speech Therapists and Audiologists. Honours research project, University of the Witwatersrand, Johannesburg.

Bernstein, C. (1992). Supervisor Social Support as a Moderator of Stress-strain Relationships. M.A. Psychology Dissertation. Johannesburg: University of the Witwatersrand.

Cherniss, C. (1980). Staff Burnout. Job Stress in the Human Services. California: Sage Publications.

Christensen, L.B. (1980). Experimental Methodology. Allyn and Bacon, Inc: Boston.

Cobb, S. (1976). Social Support as a Moderator of Life Stress. Psychosomatic Medicine, 38(5), 300-314

Cooper, C.L. \& Davidson, M.J. (1991). The Stress Survivors. Experiences of Successful Personalities. London:Grafton

Disability in the Republic of South Africa. (1987). Speech Impairment, vol 10, Commissioned by the Department of Health, for the Year of the Disabled.

Edelwich, J. \& Brodsky, A. (1980). Burnout: Stages of Disillusionment in the Helping Profession. Human Sciences Press:New York.

Fimian, M.J. Lieberman, R.J. \& Fastenau, P.S. (1991). Development and validation of an instrument to measure occupational stress in speech-language pathologists. Journal of Speech and Hearing Research, 34, 439-446.

Folkman, S., Lazarus, R.S., Gruen, R.J. \& De Longis, A. (1986) Appraisal, Coping, Health Status, and Psychological Symptoms. Journal of Personality and Social psychology, $50(3), 571-579$.

Freudenberger, H.J. (1974). Staff Burnout. Journal of Social Issues, 30, 159-165.

Handy, J.A. (1988). Theoretical and Methodological Problems Within Occupational Stress and Burnout Research. Human Relations, 41(5), 351-369.

Kersner, M. \& Stone, J. (1991). Stress in the National Health Service: A survey of three therapy groups, Stress News, 2 (4), $2-9$.

Kobasa, S. (1979). Stressful Life Events, Personality, Ill-health: An inquiry into hardiness. Journal of Social Personality, $37,1-11$.

Koeske, G.F. \& Koeske, R.D.(1989). Construct Validity of the Maslach Burnout Inventory: A Critical Review and Reconceptualisation. Journal Of Applied Behavioral Science, 25(2), 131-143

Mac Farlane, W.R. (1990). Social Support As A Moderator of the Burnout/Organisational Behavior Relationship. Honours dissertation, University of the Witwatersrand, Johannesburg.

Maslach, C. (1982). Burnout - The Cost of Caring. PrenticeHall Press: New York.

Maslach, C. \& Jackson, S. (1981). Maslach Burnout Inventory Manual. Research ed. California: Consulting Psychologists Press.

Maslach, C. \& Jackson, S. (1986). Maslach Burnout Inventory Manual. 2nd Edition. California Psychologists Press.

Miller, M.M. \& Potter, R.E. (1982). Professional Burnout among Speech Language Pathologists. ASHA, 1982, 177-181

Moos, R.H. (1987). The Social Climate Scales; A User's Guide, California: Consulting Psychologists Press.

Moos, R.H. \& Insel, P.N. (1974). Work Environment Scale. California: Consulting Psychologists Press.

Moos, R.H. (1986). Work Environment Scale Manual. California: Consulting Psychologists Press.

Moser, C. \& Kalton, G. (1971). Survey Methods in Social Investigation. 2nd ed. London: Heinemann.

Offermann, L.R. (1985). Maslach Burnout Inventory. In D Keyser \& R. Sweetland (Eds.)Test Critiques, vol III, U.S.A.: Test Corporation of America.

Oktay, J. (1992). Burnout in Hospital Social Workers Who Work With AIDS Patients. Social Work, 37(5), 432-439.

Paine, W.S. (1982). Job Stress and Burnout: Research, Theory and Intervention Perspectives. Beverly Hills: Sage Publications.

Phiyega, M.V. (1992). Community Development-The South African Welfare Challenge: A respon'se by the South African National Council For Child and Family Welfare. The Social Work Practitioner-Researcher, 3, 3-7.

Ratcliff, N. (1988). Stress and Burnout in the Helping Professions. Social Casework, 69(3), 147-154.

Ross, R.R. Altmaier, E.M., \& Russell, D.W. (1989). Job Stress, Social Support, and Burnout Among Counseling Center Staff. Journal of Counselling Psychology, 36(4), 464-470. 
Savicki, V. \& Cooley, E. (1987). The Relationship of Work Environment And Client Contact to Burnout in Mental Health Professionala. Journal of Counselling and Development. 65, 249-252.

Steenekamp, A.M. (1993) Editorial. Communiphon, no.305, 3-6.
Tuomi, S.P. (1993). Quality assurance in Speech- Language Pathology and Audiology. The South African Experience. Communiphon, no. 305, 10-13.

Van Der Ploeg, H.M, Van Leeuwen, J.J, \& Kwee, M.G.T. (1990). Burnout among Dutch Psychotherapists. Psychological Reports, 67, 107-112

\section{Appendix I}

\section{Dear Speech Pathologist/ Audiologist}

As a requirement for my degree, I am conducting a study of occupational stress among South African SpeechLanguage Pathologists and Audiologists, and the specific work situations which clinicians are currently experiencing. I believe that therapists working in this country are having to deal not only with the day-to -day stresses of all helping professionals but also with the unique economic and socio-political conditions prevalent in our society.

Your participation in this study will add to our knowledge and understanding of work stress within our profession. Furthermore, depending on the level of stress found to be experienced, intervention strategies may need to be recommended both at a training and occupational level. It would therefore be highly appreciated if each one of you could take the time to fill out the enclosed questionnaire thereby helping to ensure that the findings of the study are representative of the profession of Speech-Language Pathology and Audiology.

Please would you assist by answering each item as openly and honestly as possible, and when completed, sealing the questionnaire in the envelope provided, and posting it back to me by the 24th of April at the latest. There are no wrong or right answers. Rather, what I am looking for, is the response that is most accurate for you.

Please note that your responses will be kept strictly confidential and you will remain anonymous as your name is not required anywhere on this questionnaire. Supplied with this questionnaire is a postcard with your name written on it. Kindly return the postcard separately, informing me that the questionnaire has been returned and no follow-up questionnaires will be sent to you.

If you are interested in the results or have any questions, I will be only too willing to give you feedback at a mutually acceptable time.

I can be contacted at telephone number: 453-7025.

Thank you again for your time and cooperation.

Yours sincerely

Marilyn Swidler

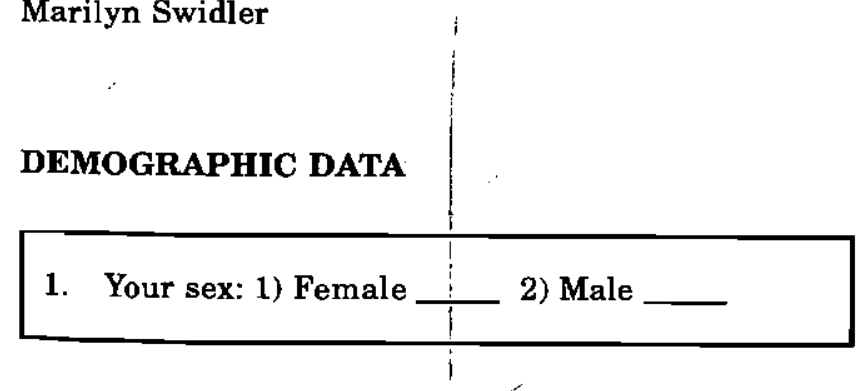

2. How many years have you worked in the profession since graduation?

3. Please check the main work setting in which you are currently employed.
a) Hospital-Clinic
b) Private Clinic
c) School
d) Insitution
e) University
f) Private Practise
g) Other

4. As of this time, my client caseload per week is:
a) 1-15
b) $16-30$
c) $31-45$
d) $46-60$
e) 60 or more

5. Most of my clients have defects of: (select only one).
a) Articulation b) Language
c) Language/learning difficulties
d) Aphasia e) Traumatic Brain Injury
f) Degenerative neurological disorders
g) Dysphagia h) Fluency
i) Peripheral Hearing Disorders
j) Central Hearing Disorders
k) Mental Retardation
1) Other (Specify) 
6. Are the majority of your caseload:

a) Mildly Impaired

b) Moderately Impaired

c) Severely Impaired

7. Do you mainly treat adults or children?
a) Adults
b) Children

c) Both Equally

8. Do you work as an audiologist or speech-language pathologist?

a) Audiologist only

b) Speech-language pathologist only

c) Audiologist and Speech-language pathologist

9. Estimate percentage of work week devoted to paperwork (e.g., writing Individualised Educational Programs, reports, correspondence.)
a) $0-10 \%$
b) $11-20$
c) $21-30 \%$
d) $31-40 \%$
e) $41-50 \%$
f) $51 \%$ or more

10. Are the majority of your clients:

a) English Speaking

b) Afrikaans Speaking

c) Speak an African/Black Language

\section{OPEN-ENDED QUESTIONS}

1. (a) Are there any particular factors at work that you find stressful?

| I YES | | NO

(b) If yes, please describe.

2. (a) Do you feel that any broader societal factors contribute to your experience of stress e.g. socioeconomic, politico-cultural factors?

\section{I YES | । NO}

(b) If yes, please elaborate.
3. What strategies do you use to cope with stress?

4. Do you feel that a stress management course should be incorporated into the training curricula of speech-language and hearing therapists, or do you think this is unnecessary?

5. Do you think that a stress-management course/ workshop should be made available for qualified speech-language and hearing therapists?

\section{WORK ENVIRONMENT}

The following statements are about the place in which you work. The statements are intended to apply to all work environments. However, some words may not be quite suitable for your work environment, for example the term "supervisor" can also refer to a manager, department head, or the person or persons to whom an employee reports.

You are to decide which statements are true of your work environment and which are false. If you think the statement is True or mostly true of your work environment, make an $\mathrm{X}$ in the corresponding box in the column labelled True. If you think the statement|is False or mostly false of your work environment, make an X in the corresponding box in the column labelled false. If $a$ statement is not applicable to your work environment please mark the N/A column. Please be sure to answer every statement.

\section{SECTION A}

1. People go out of their way to help a new employee feel comfortable.

2. The atmosphere is somewhat impersonal.

3. People take a personal interest in éach other.

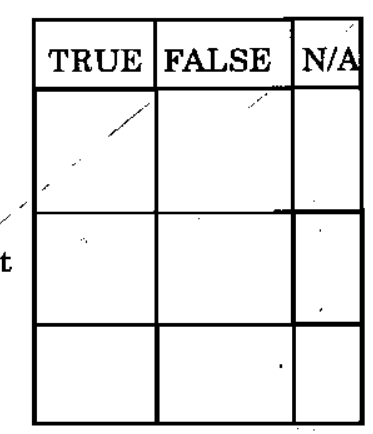


4. Employees rarely do things together after work.

5. People are generally frank about how they feel.

6. Employees often eat lunch together.

7. Employees who differ greatly from the others in the organisation don't get on well.

8. Employees often talk to each other about their personal problems.

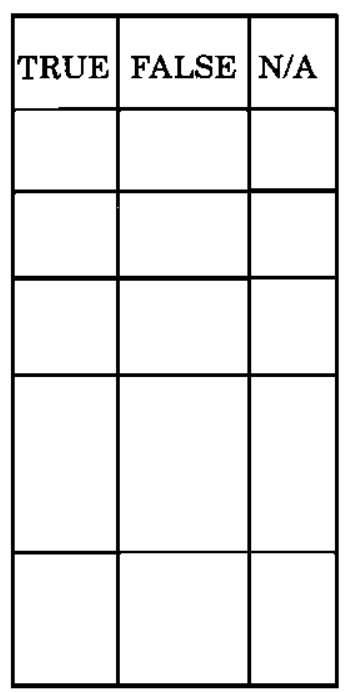

\section{SECTION B}

1. Supervisors really stand up for their people.

2. Employees discuss their personal problems with supervisors.

3. Supervisors expect far too much from their employees.

4. Employees generally feel free to ask for a raise.

5. Supervisors often criticise employees over minor things.

6. Supervisors usually give full credit to ideas contributed employees.

7. Supervisors tend to discourage criticisms from employees.

8. Supervisors tend to talk down to employees:

9. Supervisors usually compliment an employee when he does something well.

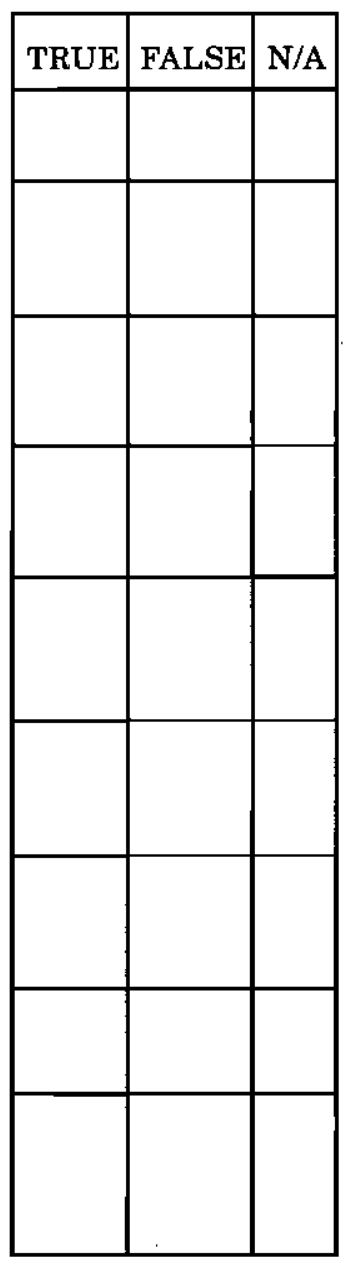

\section{SECTION C}

1. People often have to work overtime to get their work done.

2. People cannot afford to relax.

3. You can take it easy । and still get your work done.
4. There is no time pressure.

5. It is very hard to keep up with your workload.

6. Nobody works too hard.

7. There are always deadlines to be met.

8. There is a constant pressure to keep working.

9. There always seems to be an urgency about everything.

\section{HUMAN SERVICES SURVEY}

The purpose of this section is to discover how Speechlanguage Pathologists and Audiologists as human service or helping professionals, view their jobs and the people with whom they work closely. The term "client" refers to the people for whom you provide service, care, treatment or instruction -- even though you may use another term in your work, eg., patient, student, employee, etc.

There are 22 statements of job-related feelings. Please read each statement carefully and decide if you ever feel this way about your job. If you have never had this feeling, write a " 0 " (zero) before the statement. If you have had this feeling, indicate how often you feel it by writing the number (from 1 to 6 ) that best describes how frequently you feel this way.

\section{HOW OFTEN}

\begin{tabular}{|c|c|c|c|c|c|c|}
\hline $\begin{array}{l}0 \\
\text { Never }\end{array}$ & $\begin{array}{l}1 \\
\text { A few } \\
\text { times } \\
\text { a year } \\
\text { or less }\end{array}$ & $\begin{array}{l}2 \\
\text { Once a } \\
\text { month } \\
\text { or less }\end{array}$ & $\begin{array}{l}3 \\
\text { A few } \\
\text { times } \\
\text { a } \\
\text { month }\end{array}$ & $\begin{array}{l}4 \\
\text { Once a } \\
\text { week }\end{array}$ & $\begin{array}{l}5 \\
\text { A few } \\
\text { times } \\
\text { a } \\
\text { week }\end{array}$ & $\begin{array}{l}6 \\
\text { Every } \\
\text { day }\end{array}$ \\
\hline
\end{tabular}

\section{HOW OFTEN}

\section{0 - 6 STATEMENTS}

1. _ I feel emotionally drained from my work.

2. - I feel used up at the end of the workday.

3. _ I feel fatigued when I get up in the morning and have to face another day on the job.

4. _ I can easily understand how my clients feel about things.

5. _ I feel I treat some clients as if they were impersonal objects

6. Working with people all day is really a strain for me.

7. I I deal very effectively with problems of my clients.

8. I I feel burned out from my work.

9. _ I feel I'm positively influencing other people's lives through my work.

10. I've become more callous toward people since I took this job. 
11. I worry that this job is hardening me emotionally.

12. _ I feel very energetic.

13. _ I f feel frustrated by my job.

14. - I feel I'm working too hard on my job.

15. _ I don't really care what happens to some clients.

16. __ Working with people directly puts too much stress on me.

17. I can easily create a relaxed atmosphere with my clients.
18. _ I feel exhilarated after working closely with my clients.

19. __ I have accomplished many worthwhile things in this job.

20. I I feel like I'm at the end of my rope.

21. _ In my work, I deal with emotional problems very calmly.

22. _ I feel clients blame me for some of their problems.

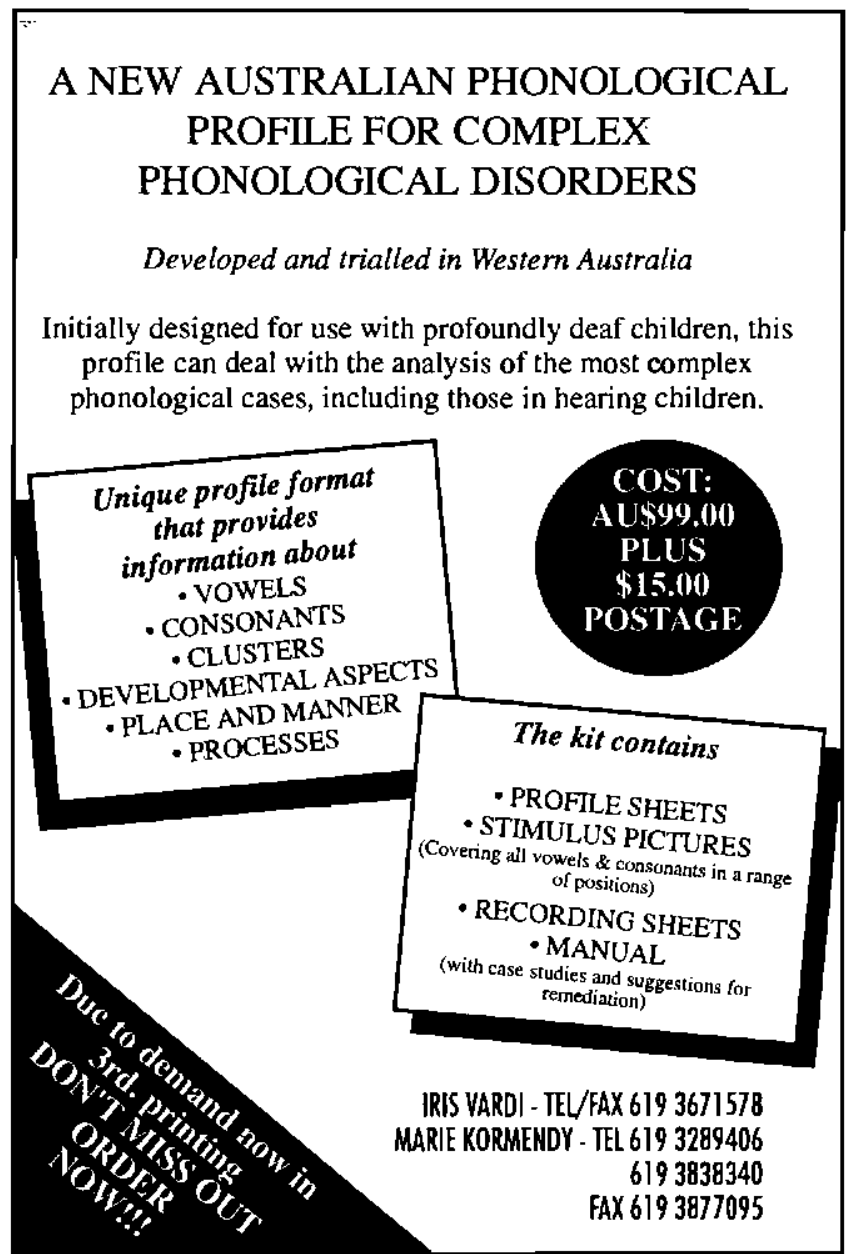

